\title{
The Empty Too: Language and Philosophy in the Works of Samuel Beckett
}

\author{
Broomfield, Arthur. (2014). \\ Newcastle: Cambridge Scholars Publishing.
}

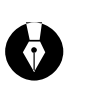

Marcelo Lara

Universidad de Buenos Aires, Argentina

El trabajo de Broomfield nos lleva hacia la construcción y problematización de un espacio que aloja la posibilidad de pensar la escritura de Beckett como un camino alternativo para acercarse a la pregunta sobre el ser. De este modo, la filosofía inunda -y es inundada por- la obra del irlandés, extendiendo los márgenes del pensamiento como un gesto propio de su arte. En este sentido, la propuesta del autor se dirige hacia una lectura de la obra Samuel Beckett que trasciende lo que se ha dicho hasta el momento, tanto en el campo de la filosofía como en la literatura. Así el texto de Broomfield puede ser ubicado en una serie de estudios sobre la operación crítica y deconstructiva que los escritos del autor irlandés realiza sobre el carácter afirmativo del lenguaje. Así, podemos poner el trabajo de Broomfield en una continuidad de acercamientos a la obra de Samuel Beckett, como, entre otros, el libro de Richard Lane, Beckett and Philosophy, texto en el que se reúnen ensayos que nos acercan a las preocupaciones de la filosofía francesa y alemana con las de la obra beckettiana.

The Empty Too: Language and Philosophy in the Works of Samuel Beckett está dividido en cinco capítulos en los que se problematiza la obra de Beckett en medio de la filosofía y más allá de ella, a partir de la autosuficiencia del lenguaje y su irreductibilidad a la mera palabra.

Un primer capítulo introductorio, "The Real and the Other from Plato, Through Derrida, to Beckett" ubica al autor irlandés en relación con la filosofía de Platón, tomando al filósofo griego como precursor de Beckett. En este marco, emerge la discusión sobre el problema de lo que deviene inteligible a partir de la deducción, y de aquello que es percibido por los sentidos. De esta manera, se presenta la tensión entre el lenguaje como representación del mundo, y el lenguaje como lo real en términos de independencia de la representación, aunque con sentido gramatical y lógico. En esta cuestión Broomfield nos lleva a la pregunta formulada en el Timeo por lo que es siempre y no deviene, y lo que continuamente deviene, pero nunca es. El ser, en este sentido, no puede ser percibido empíricamente por los sentidos, sino a través del entendimiento. Dicho principio sería aquello que une el pensamiento de Platón y de Beckett.

A partir de la idea de que la percepción de los sentidos es lo otro que perturba lo real -en el pensamiento convencional lo otro es lo que es distinto de lo que percibimos- tanto en el irlandés como en el griego se expande el trabajo milimétrico de Broomfield sobre cuatro textos centrales en la obra de Beckett.

Asimismo, en este primer capítulo aparecerá la contribución que realiza Derrida a través del método deconstructivo al pensamiento sobre el lenguaje y el significado, así como sobre la relación entre la palabra y su referente. Pero el autor no se queda en la mera descripción sino que se propone identificar el punto en el que Derrida calcula mal [miscalculates], a partir del cual Beckett insiste en avanzar, en ir más allá. Ahora bien, ese punto problemático será específicamente el problema de ubicar la differance en el juego entre lenguaje y percepción. Allí Broomfield detecta que el mundo de las percepciones aparece con cierta ventaja sobre lo inteligible en la crítica de Derrida, bloqueando la posibilidad de explorar el lenguaje como lo real, abriendo el espacio de una relación confusa entre la palabra y la percepción, haciendo que la palabra sea la que debe traducir percepciones cambiantes e inestables al lenguaje.

The Empty Too: Language and Philosophy in the Works of Samuel Beckett trabaja cuatro textos fundamentales de la obra beckettiana. En primer lugar toma la película de 1965 Film con el fin de proponer una lectura que toma el pensamiento de Berkeley, pero que se desplaza de su negación de la existencia de hechos o cosas. En este sentido, Film podría ser vista como 
un capítulo de la tesis filosófica de Beckett que se propone aislar la percepción de lo real y del lenguaje.

A continuación, el libro de Broomfield trabaja la obra teatral Waiting for Godot, de 1953, donde una vez más profundiza en la idea de que el lenguaje es independiente de la representación, enfatizando que para Beckett el lenguaje es lo real. Tomando la famosa crítica que sentencia que nada sucede en Esperando a Godot, aquí se afirma que efectivamente no demasiado ocurre en el mundo existencial del no-ser, aunque sí en el reino de lo real, donde el lenguaje evade cualquier asociación con las percepciones, independizándose éste de la representación, como en el caso paradigmático de las líneas finales:

VLADIMIR: ¿Qué? ¿Nos vamos?

\section{ESTRAGON: Vamos.}

(No se mueven.) $^{2}$

En tercer lugar, The Empty Too realiza un análisis de la novela How is it (1961) que comienza con una declaración de principios que, de algún modo, guía la lectura de todo el trabajo: leer Beckett a través del prisma del pensamiento de filósofos del pasado es reducir su trabajo a una cosmovisión con la que el irlandés se pelea. "How It Is in How It Is" se ocupa de precisar, entre otras cuestiones, sobre lo que Broomfield define como el "dispositivo sintáctico" de Beckett [syntactical device]. La omisión de la puntuación, por ejemplo, tiene como efecto el cambio o desvío de aquello a lo que la palabra se cree o se espera que debería representar. El escenario en el que vemos un proceso de divorcio del lenguaje de su significado, y en el que se vuelve no absurdo, sino existencia que va más allá de la mera función utilitaria de una herramienta o como un medio.

Para finalizar, Broomfield profundiza en el texto en prosa Worstward Ho, de 1983, quizás el trabajo de Beckett donde la distinción entre el lenguaje como representación y el lenguaje como lo real aparece, quizás, de manera más fuerte que en las obras analizadas en este volumen.

Beckett, en definitiva, es presentado y trabajado como un filósofo-artista que, por supuesto, ha sido influenciado por otros filósofos -de hecho, algunas cuestiones de su pensamiento coinciden con aquellos. Sin embargo, al mismo tiempo, podemos leer en su obra los puntos en los que se separa de esos cruces, convergencias o cercanías, en los que su escritura produce un pensamiento que va más allá. 